\title{
Effect of rifampin and itraconazole on the pharmacokinetics of zanubrutinib (a Bruton's tyrosine kinase inhibitor) in Asian and non-Asian healthy subjects
}

\author{
Song $\mathrm{Mu}^{1} \cdot$ Zhiyu Tang $^{1} \cdot$ William Novotny $^{2} \cdot$ Manal Tawashi $^{3} \cdot$ Ta-Kai Li $^{4} \cdot$ Ying Ou $^{1} \cdot$ Srikumar Sahasranaman $^{1}(\mathbb{C}$
}

Received: 26 July 2019 / Accepted: 14 December 2019 / Published online: 26 December 2019

(C) The Author(s) 2019

\begin{abstract}
Purpose Zanubrutinib (BGB-3111) is a potent Bruton's tyrosine kinase inhibitor with promising clinical activity in B-cell malignancies. Zanubrutinib was shown to be mainly metabolized through cytochrome P450 3A (CYP3A) in vitro. We evaluated the effect of steady-state rifampin (a strong CYP3A inducer) and steady-state itraconazole (a strong CYP3A inhibitor) on the pharmacokinetics (PK), safety, and tolerability of zanubrutinib in healthy Asian and non-Asian subjects.

Methods In this open-label, two-part clinical study, 20 participants received a single oral dose of zanubrutinib (320 mg) and oral rifampin $(600 \mathrm{mg})$ in Part A, and 18 participants received a single oral dose of zanubrutinib $(20 \mathrm{mg})$ and oral itraconazole $(200 \mathrm{mg}$ ) in Part B. Serial blood samples were collected after administration of zanubrutinib alone and zanubrutinib in combination with rifampin or itraconazole for the measurement of PK parameters.

Results Coadministration with rifampin decreased $\mathrm{AUC}_{0-\infty}$ of zanubrutinib by 13.5 -fold and $C_{\max }$ by 12.6 -fold. Coadministration with itraconazole increased the $\mathrm{AUC}_{0-\infty}$ of zanubrutinib by 3.8-fold and $C_{\max }$ by 2.6-fold. The PK of zanubrutinib was consistent between Asian and non-Asian subjects, and zanubrutinib was well tolerated in this study.

Conclusions These results confirm that zanubrutinib is primarily metabolized by CYP3A in humans. The PK of zanubrutinib was comparable between Asian and non-Asian subjects and, therefore, no dose modifications are necessary for zanubrutinib in these ethnic populations.
\end{abstract}

Keywords Clinical pharmacology $\cdot$ Clinical trials $\cdot$ Drug-drug interactions $\cdot$ Oncology $\cdot$ Pharmacokinetics and drug metabolism

\section{Introduction}

The B-cell receptor signaling pathway is essential for normal B-cell development but is also implicated in the survival and proliferation of malignant B cells [1-4]. Inhibition of

Electronic supplementary material The online version of this article (https://doi.org/10.1007/s00280-019-04015-w) contains supplementary material, which is available to authorized users.

Srikumar Sahasranaman

sri.sahasranaman@beigene.com

1 Clinical Pharmacology, BeiGene USA, 2955 Campus Drive, Suite 300, San Mateo, CA 94403, USA

2 Clinical Development, BeiGene USA, San Mateo, CA, USA

3 Clinical Operations, BeiGene USA, San Mateo, CA, USA

4 Drug Safety and Pharmacovigilance, BeiGene USA, San Mateo, CA, USA
B-cell receptor signaling has recently been established as an effective approach for the management of B-cell malignancies [2]. Bruton's tyrosine kinase (BTK) is a key component of the B-cell receptor signaling pathway [3], and the firstgeneration BTK inhibitor, ibrutinib, has become a standard of care in chronic lymphocytic leukemia/small lymphocytic lymphoma (CLL/SLL), mantle cell lymphoma, and Waldenström macroglobulinemia [5-13].

Zanubrutinib (BGB-3111) is an investigational, highly specific, next-generation BTK inhibitor that has demonstrated encouraging clinical activity in phase $1 / 2$ studies [14-17] and is currently in phase 3 testing for multiple indications [18-20]. In patients with B-cell malignancies, zanubrutinib was generally well tolerated at total daily doses ranging from 40 to $320 \mathrm{mg}$, and the recommended phase 2 dose is $160 \mathrm{mg}$ administered twice daily [16]. Pharmacokinetic (PK) data showed that zanubrutinib was rapidly absorbed after oral administration, with $C_{\max }$ observed at 
approximately $2 \mathrm{~h}$ after dosing in patients with B-cell malignancies. Exposure to zanubrutinib increased in a dose-proportional manner from total daily doses of 40-320 mg and the mean half-life of zanubrutinib was approximately $2-4 \mathrm{~h}$ with minimal accumulation observed after repeated dosing. Total exposure was comparable when $320 \mathrm{mg}$ total daily dose was administered as $160 \mathrm{mg}$ twice daily or $320 \mathrm{mg}$ once daily [21]. In human liver microsomes, the oxidative metabolism of zanubrutinib is largely mediated through the cytochrome P450 3A (CYP3A) pathway (unpublished data).

Drug-drug interactions (DDI) with CYP3A-mediated metabolism are particularly problematic in patients with B-cell malignancies such as CLL/SLL because these patients are at risk for systemic fungal infections due to underlying disease-related immune dysfunction and therapy-related immunosuppression [22]. Prophylactic or therapeutic use of azole anti-fungals is common in CLL/SLL [23], and the agents in this therapeutic class (e.g., voriconazole, posaconazole) are moderate-to-strong inhibitors of CYP3A [24, 25]. Because of the potential concomitant usage of these agents with zanubrutinib, it is important to understand the DDI potential between zanubrutinib and CYP3A inhibitors and inducers. Hence, the current study was designed to evaluate the effect of rifampin (a strong CYP3A inducer) and itraconazole (a strong CYP3A inhibitor) on the PK of zanubrutinib in healthy subjects. Rifampin and itraconazole were chosen because they are a preferred CYP3A inducer and inhibitor, respectively, in DDI studies [26, 27].

Due to the anticipated PK variability for zanubrutinib as a CYP3A substrate and underlying comorbidities in cancer patients, PK comparisons across patient studies to understand potential ethnic differences could be challenging. To assess ethnic differences in PK more robustly, it is ideal to use a single protocol that controls extrinsic factors and that can be uniformly applied to the different ethnic populations. To this end, this DDI study included healthy Asian and nonAsian subjects to facilitate comparison of zanubrutinib PK across different ethnic groups and to help support dose selection of zanubrutinib in clinical studies conducted in Asia.

\section{Methods}

\section{Study design and subjects}

The study was conducted in accordance with the International Conference on Harmonisation, Good Clinical Practice, and the Declaration of Helsinki guidelines. All participants provided written informed consent prior to study entry. The protocol was reviewed and approved by the Institutional Review Board at the study center.

This was an open-label, parallel-group, fixed-sequence study in healthy male and female subjects conducted in two parts, Part A and Part B. Part A investigated the effect of CYP3A induction by steady-state rifampin on the singledose PK of $320 \mathrm{mg}$ zanubrutinib, and Part B investigated the effect of CYP3A inhibition by steady-state itraconazole on the single-dose PK of $20 \mathrm{mg}$ zanubrutinib.

Healthy male or female subjects, aged between 18 and 65 years, inclusive, with a body mass index between 18.0 and $32.0 \mathrm{~kg} / \mathrm{m}^{2}$, inclusive, who were of either first- or second-generation Asian descent (defined as an individual whose biological parents or four biological grandparents were born in one of the following East Asian countries or territories: China, Japan, Korea, Taiwan, Hong Kong, Mongolia, Cambodia, or Vietnam); or non-Asian descent (defined as an individual whose biological parents and four biological grandparents were not born in one of the previously listed East Asian countries), were selected according to the inclusion and exclusion criteria listed in the protocol.

It was planned that approximately 40 subjects ( 20 in each part) would be enrolled to ensure that at least 36 subjects (18 in each part) completed the study. It was planned that approximately one-third of subjects enrolled in the study would be Asian, and approximately two-thirds would be non-Asian.

\section{Treatments}

In Part A, participants received a single oral dose of zanubrutinib (320 mg) in the fasted state on Day 1 and Day 10. Oral rifampin $(600 \mathrm{mg} / \mathrm{day}$, Rifampin, VersaPharm Inc., Marietta, GA, USA) was administered once daily in the fasted state on Days 3 through 11. In Part B, participants received a single oral dose of zanubrutinib $(20 \mathrm{mg})$ in the fasted state on Day 1 and Day 6. Oral itraconazole (200 mg/ day, Sporanox ${ }^{\circledR}$ capsules, Janssen Pharmaceuticals, Titusville, NJ, USA) was administered once-daily approximately 30 min after completing a meal on Days 3, 4, 5, and 7, and in the fasted state on Day 6.

\section{Study assessments}

\section{Sample collection}

Serial blood samples were collected with zanubrutinib alone and when combined with rifampin or itraconazole for the measurement of zanubrutinib plasma concentrations. Plasma samples were collected at predose, 0.5, 1, 1.5, 2, 3, 4, 6, 8, $12,24,36$, and $48 \mathrm{~h}$ postdose on Day 1 and Day 10 in Part A and on Day 1 and Day 6 in Part B.

\section{Bioanalytical methodology}

Plasma concentrations of zanubrutinib were determined using validated high-performance liquid chromatography 
coupled with tandem mass spectrometry (HPLC-MS/MS) (Xenobiotic Laboratories, NJ, USA). Protein precipitation was utilized to extract the analyte and internal standard from human plasma containing dipotassium ethylenediaminetetraacetic acid (K2EDTA) as anticoagulant. The analytical method utilized a reversed-phase HPLC column (Supelco Ascentis Express C18 $20 \times 2.1 \mathrm{~mm}, 2.7 \mu \mathrm{m}$ ) with a gradient flow of $0.1 \%$ formic acid in water (Mobile Phase A) and methanol:acetonitrile (1:1) (Mobile Phase B) at a rate of $0.5 \mathrm{~mL} / \mathrm{min}$. The analyte and internal standard were detected using an AB Sciex API-4000 LC-MS/MS system equipped with a positive ESI ion detection.

The calibration range of zanubrutinib in the assay was 1.00 to $1000 \mathrm{ng} / \mathrm{mL}$ using a $50 \mu \mathrm{L}$ aliquot of plasma, with the lower limit of quantification of $1.00 \mathrm{ng} / \mathrm{mL}$. The performance of calibration standards showed a good linearity from 1.00 to $1000 \mathrm{ng}$, with the coefficient of correlation $(r)>0.990$, and the cumulative bias ranged from -2.00 to $3.00 \%$ and the cumulative precision was $\leq 5.34 \%$ coefficient of variation $(\mathrm{CV})$. The results indicate the method to be sensitive, selective, accurate, and reproducible.

\section{Pharmacokinetic analysis}

Noncompartmental PK analysis was conducted using the Phoenix ${ }^{\circledR}$ WinNolin ${ }^{\circledR}$ software (Version 6.4). PK parameters were derived for zanubrutinib alone and in combination with rifampin or itraconazole, including area under the plasma concentration-time curve (AUC), maximum observed plasma concentration $\left(C_{\max }\right)$, time of the maximum observed plasma concentration $\left(t_{\max }\right)$, apparent terminal elimination half-life $\left(t_{1 / 2}\right)$, apparent total oral clearance $(\mathrm{CL} / F)$, and apparent volume of distribution during the terminal elimination phase $\left(V_{\mathrm{z}} / F\right)$. Log-transformed area under the curve from time 0 extrapolated to time $t\left(\mathrm{AUC}_{0-t}\right)$, area under the curve from time 0 extrapolated to infinite time $\left(\mathrm{AUC}_{0-\infty}\right)$, and $C_{\max }$ of zanubrutinib were analyzed using a mixed model for each part of the study, including treatments as a fixed effect and subject as a random effect. Estimates of geometric mean ratios (GMRs) and the corresponding 90\% confidence intervals (CIs) were derived for the comparisons of $\mathrm{AUC}_{0-\infty}$, and $C_{\max }$ as follows:

Part A: zanubrutinib coadministration with rifampin (test) versus zanubrutinib alone (reference),

Part B: zanubrutinib coadministration with itraconazole (test) versus zanubrutinib alone (reference).

\section{Safety analysis}

Treatment-emergent adverse events (TEAEs) are summarized by part, treatment, National Cancer Institute Common Terminology Criteria for Adverse Events (v4.03) grade, and relationship to study drugs (zanubrutinib, rifampin, and itraconazole). The frequency of TEAEs is summarized by part, treatment, and Medical Dictionary for Regulatory Activities (MedDRA) system organ class (SOC) and preferred term. The summary and frequency TEAE tables are presented for all causalities and for those TEAEs considered related to the study drugs.

\section{Results}

\section{Demographics}

In Part A, 20 subjects were enrolled, and 19 subjects completed the study; in Part B, 18 subjects were enrolled, and 17 subjects completed the study. All subjects in Parts A and $\mathrm{B}$ were included in the safety and PK analysis sets. Baseline demographics for participants in Part A and Part B are shown in Table 1. The mean participant age was 40 years, and $76.3 \%$ were male. In Part A and Part B, $40.0 \%$ and $44.4 \%$, respectively, were Asian. All Asian patients included in the study were of first-generation Chinese descent.

\section{Pharmacokinetics}

\section{Part A}

The plasma concentration-time profiles and PK parameters of zanubrutinib in the absence and presence of rifampin are shown in Fig. 1a and Table 2, respectively. Plasma concentrations of zanubrutinib were significantly lower following coadministration of $320 \mathrm{mg}$ zanubrutinib with $600 \mathrm{mg}$ rifampin compared with the administration of $320 \mathrm{mg}$ zanubrutinib alone. As shown in Table 2, GMRs (90\% CI) of $\mathrm{AUC}_{0-\infty}$ and $C_{\max }$ for zanubrutinib were $7.4 \%$ (6.0-9.1) and $7.9 \%$ (6.6-9.5), respectively. These results represented a decreased exposure of 13.5-fold for $\mathrm{AUC}_{0-\infty}$, and 12.6fold for $C_{\max }$ when zanubrutinib was co-administered with rifampin. The geometric mean apparent $t_{1 / 2}$ of zanubrutinib was shorter following coadministration of rifampin $(4.8 \mathrm{~h})$ compared to administration of zanubrutinib alone $(6.8 \mathrm{~h})$. $\mathrm{AUC}_{0-t}$ values were consistent with $\mathrm{AUC}_{0-\infty}$ values because of the short half-life of zanubrutinib, and hence only AUC $0-\infty$ values are presented in this manuscript. Apparent clearance $(\mathrm{CL} / F)$ was increased from 93 to $1249 \mathrm{~L} / \mathrm{h}$, and this likely reflects a significant decrease in bioavailability $(F)$ of zanubrutinib when coadministered with rifampin.

The PK parameters of zanubrutinib were comparable between Asian and non-Asian subjects following administration of $320 \mathrm{mg}$ zanubrutinib alone on Day 1 as well as coadministration with $600 \mathrm{mg}$ rifampin on Day 10 (Supplementary Table 1 and Fig. 2a, b). 
Table 1 Summary of participant demographics at screening

\begin{tabular}{lccc}
\hline & Part A $(N=20)$ & Part B $(N=18)$ & Overall $(N=38)$ \\
\hline Age, years & & & \\
Mean (SD) & $39(9.6)$ & $42(10.6)$ & $40(10.1)$ \\
Sex, $n(\%)$ & $15(75.0)$ & $14(77.8)$ & $29(76.3)$ \\
Male & $5(25.0)$ & $4(22.2)$ & $9(23.7)$ \\
Female & & & $16(42.1)$ \\
Race, $n(\%)$ & $8(40.0)$ & $8(44.4)$ & $5(13.2)$ \\
Asian & $4(20.0)$ & $1(5.6)$ & $16(42.1)$ \\
Black or African American & $7(35.0)$ & $9(50.0)$ & $1(2.6)$ \\
White & $1(5.0)$ & 0 & $5(13.2)$ \\
Multiple & $2(10.0)$ & $3(16.7)$ & $33(86.8)$ \\
Ethnicity & $18(90.0)$ & $15(83.3)$ & $78.6(12.5)$ \\
Hispanic or Latino & & & \\
Not Hispanic or Latino & $76.6(8.75)$ & $81.0(15.6)$ & $174(10.6)$ \\
Weight, kg & & $174(12.7)$ & $26.0(2.39)$ \\
Mean (SD) & $173(8.5)$ & $26.5(2.93)$ & \\
Height, cm & & & \\
Mean (SD) & $25.5(1.73)$ & & \\
BMI, kg/m & & & \\
Mean (SD) & & & \\
\hline
\end{tabular}

$B M I$ body mass index, $N$ number of subjects, $Q D$ once daily, $S D$ standard deviation

Part A, Day 1: single oral dose of $320 \mathrm{mg}$ zanubrutinib; Days 3 to 9 and 11: oral dose of $600 \mathrm{mg}$ rifampin QD. Day 10: single oral dose of $320 \mathrm{mg}$ zanubrutinib coadministered with $600 \mathrm{mg}$ rifampin QD

Part B, Day 1: single oral dose of $20 \mathrm{mg}$ zanubrutinib; Days 3 to 5 and 7: oral dose of $200 \mathrm{mg}$ itraconazole QD

\section{Part B}

The plasma concentration-time profiles and PK parameters of zanubrutinib in the absence and presence of itraconazole are shown in Fig. 1b and Table 3, respectively. Plasma concentrations of zanubrutinib were significantly higher following coadministration of $20 \mathrm{mg}$ zanubrutinib with $200 \mathrm{mg}$ itraconazole than the administration of $20 \mathrm{mg}$ zanubrutinib alone. As shown in Table 3, GMRs $(90 \% \mathrm{CI})$ for $\mathrm{AUC}_{0-\infty}$ for zanubrutinib was $378 \%$ (344-415), respectively. The GMR (90\% CI) for zanubrutinib $C_{\max }$ was $257 \%$ (226-291). These results represented an increased exposure of 3.8-fold for $\mathrm{AUC}_{0-\infty}$, and 2.6-fold for $C_{\max }$ when zanubrutinib was co-administered with itraconazole. The geometric mean apparent $\mathrm{t}_{1 / 2}$ of zanubrutinib was longer following coadministration of $20 \mathrm{mg}$ zanubrutinib with $200 \mathrm{mg}$ itraconazole $(4.3 \mathrm{~h})$ compared to administration of $20 \mathrm{mg}$ zanubrutinib alone $(2.2 \mathrm{~h})$. However, as the terminal elimination phase of zanubrutinib may not have been adequately characterized with the 20-mg dose (due to concentrations being below the limit of quantification beyond $12 \mathrm{~h}$ post-dose), the increase in $t_{1 / 2}$ following co-administration with itraconazole should be interpreted with caution.

The PK of zanubrutinib was comparable between Asian and non-Asian subjects following administration of $20 \mathrm{mg}$ zanubrutinib alone on Day 1 and coadministration with $200 \mathrm{mg}$ itraconazole on Day 6 (Supplementary Table 1 and Fig. 2c, d).

\section{Safety}

Zanubrutinib was well tolerated in this study. The overall incidence of TEAEs was low-less than $30 \%$ in both Part A and Part B. Single doses of $320 \mathrm{mg}$ and $20 \mathrm{mg}$ zanubrutinib administered alone or co-administered with $600 \mathrm{mg}$ rifampin and $200 \mathrm{mg}$ itraconazole, respectively, were well tolerated in healthy subjects. In both parts, no subject reported a TEAE higher than Grade 2 or an SAE, and no subject discontinued due to a TEAE. The majority of TEAEs were considered not related to the study drugs, were Grade 1 in severity, and resolved without treatment. No clinically significant changes or findings were noted in clinical laboratory evaluations, vital signs, physical examinations, or body weight in this study. No subject had a QTcF value $>450 \mathrm{~ms}$ or an increase from baseline in $\mathrm{QTcF}$ of $>60 \mathrm{~ms}$ during the study. 
Fig. 1 Arithmetic mean (+SD) zanubrutinib plasma concentration profiles following a administration of $320 \mathrm{mg}$ alone and coadministration with $600 \mathrm{mg}$ rifampin or $\mathbf{b}$ administration of $20 \mathrm{mg}$ alone and coadministration with $200 \mathrm{mg}$ itraconazole. Zanubrutinib plasma concentrations on $Y$-axis are shown on $\log$ scale
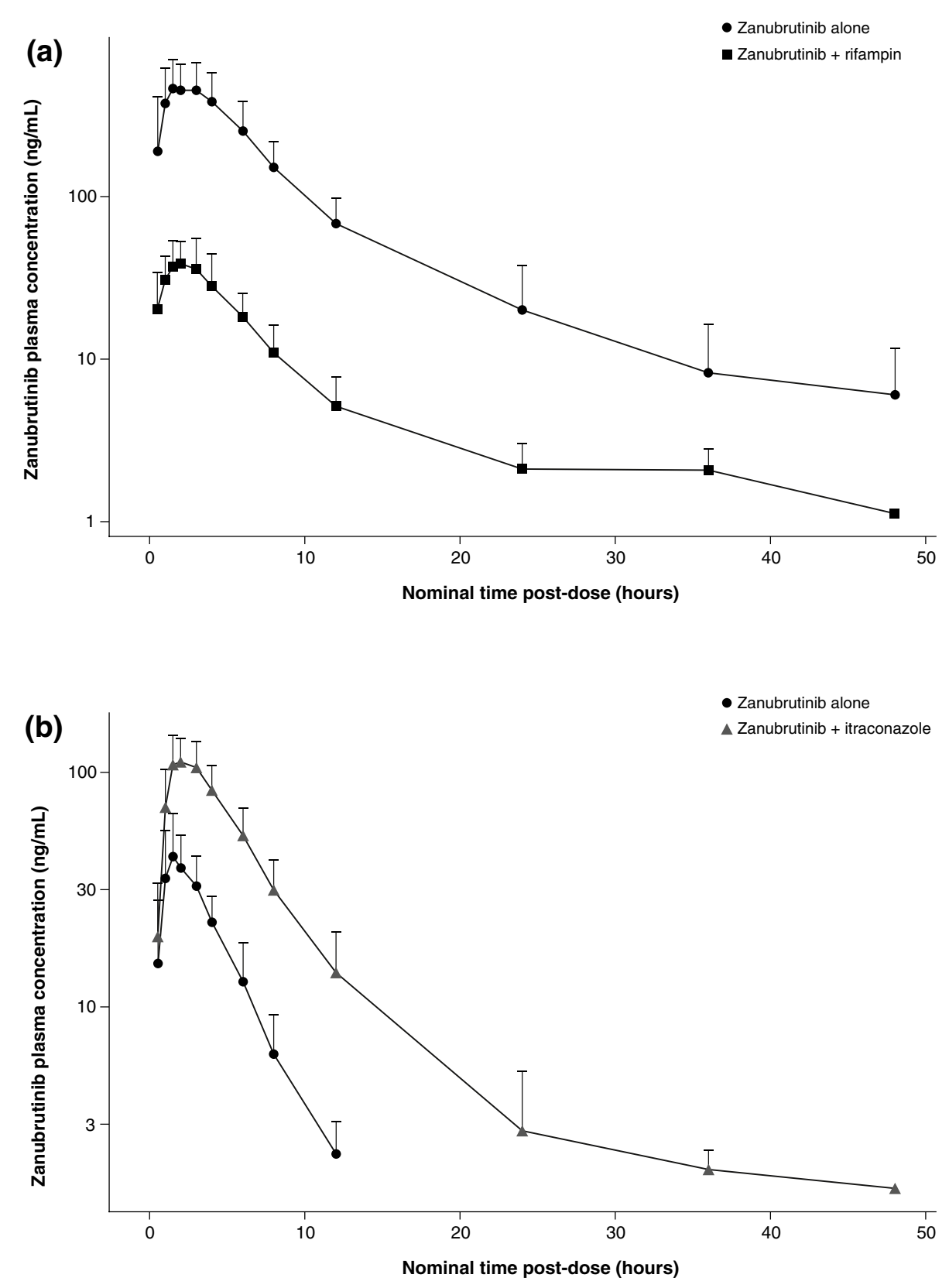

\section{Discussion}

The results from this clinical assessment confirm that zanubrutinib is primarily metabolized by CYP3A in humans and is a sensitive CYP3A substrate. Rifampin significantly affected the bioavailability and apparent clearance of zanubrutinib as reflected by a 13.5 -fold decrease in $\mathrm{AUC}_{0-\infty}$, 12.6-fold decrease in $C_{\max }$ when co-administered with rifampin. Therefore, zanubrutinib should not be co-administered with strong CYP3A inducers such as rifampin as the resulting decrease in zanubrutinib exposure may impact its efficacy.
Itraconazole increased the bioavailability and decreased the apparent clearance of zanubrutinib, as evident by the increased exposure of 3.8-fold for $\mathrm{AUC}_{0-\infty}$, and 2.6-fold for $C_{\text {max }}$. DDI with strong CYP3A inducers and inhibitors have also been reported for other BTK inhibitors such as ibrutinib (24-fold increase in AUC with ketoconazole and tenfold reduction in AUC with rifampin) and acalabrutinib (5.1-fold increase in AUC with itraconazole and $77 \%$ decrease in AUC with rifampin) $[25,28]$.

The absolute bioavailability of zanubrutinib is unknown and, therefore, based on the magnitude of interaction observed in Part A of this study and the known interactions between CYP3A inhibitors and other BTK inhibitors, a 
Table 2 Summary of pharmacokinetic parameters of zanubrutinib following administration of $320 \mathrm{mg}$ zanubrutinib alone and coadministration with 600 mg rifampin - Part A

\begin{tabular}{|c|c|c|c|}
\hline Pharmacokinetic parameter (units) & $320 \mathrm{mg}$ zanubrutinib $(n=20)$ & $\begin{array}{l}320 \mathrm{mg} \text { zanubrutinib }+600 \mathrm{mg} \\
\text { rifampin QD }(n=20)\end{array}$ & $\begin{array}{l}\text { Geometric ratio of } \\
\text { adjusted means, \% (90\% } \\
\text { CI) }\end{array}$ \\
\hline $\mathrm{AUC}_{0-\infty}, \mathrm{h} \cdot \mathrm{ng} / \mathrm{mL}($ mean CV\%) & $3524(36)(n=18)$ & $261(43)(n=18)$ & $7.4(6.0,9.1)$ \\
\hline$C_{\max }, \mathrm{ng} / \mathrm{mL}$ & $532(40)$ & $42(41)$ & $7.9(6.6,9.5)$ \\
\hline$t_{\max }^{\mathrm{b}}, \mathrm{h}$ & $2.0(0.5-6.0)$ & $2.0(0.5-4.0)$ & - \\
\hline$t_{1 / 2}, \mathrm{~h}$ & $6.8(54)$ & $4.8(91)$ & - \\
\hline $\mathrm{CL} / F, \mathrm{~L} / \mathrm{h}$ & $93(36)$ & $1249(43)$ & - \\
\hline$V_{\mathrm{z} /} \mathrm{F}, \mathrm{L}$ & $914(73)$ & $8665(70)$ & - \\
\hline
\end{tabular}

$A U C$ area under the plasma concentration-time curve, $C L / F$ apparent total oral clearance, $C_{\max }$ maximum plasma concentration, $Q D$ once daily, $t_{1 / 2}$ apparent terminal elimination half-life, $t_{\max }$ time of the maximum observed plasma concentration, $V_{t} / F$ apparent volume of distribution during the terminal elimination phase

${ }^{a}$ Geometric mean data (\% coefficient of variation) except where otherwise noted

${ }^{\mathrm{b}}$ Median (min-max)

${ }^{c}$ Ratio of zanubrutinib in combination with rifampin versus zanubrutinib alone

Table 3 Summary of pharmacokinetic parameters of zanubrutinib following administration of $20 \mathrm{mg}$ zanubrutinib alone and coadministration with $200 \mathrm{mg}$ itraconazole - Part B

\begin{tabular}{llll}
\hline $\begin{array}{l}\text { Pharmacokinetic } \\
\text { parameter (units) }\end{array}$ & $\begin{array}{l}20 \mathrm{mg} \text { zanubrutinib } \\
(n=18)\end{array}$ & $\begin{array}{l}20 \mathrm{mg} \text { zanubrutinib }+200 \mathrm{mg} \\
\text { itraconazole QD }(n=18)\end{array}$ & $\begin{array}{l}\text { Geometric ratio of } \\
\text { adjusted means, \% (90\% } \\
\left.\mathrm{CI}^{\mathrm{c}}\right)^{\mathrm{c}}\end{array}$ \\
\hline $\mathrm{AUC}_{0-\infty}, \mathrm{h} \cdot \mathrm{ng} / \mathrm{mL}$ & $184(29)$ & $693(31)$ & $378(344,415)$ \\
$C_{\max }, \mathrm{ng} / \mathrm{mL}$ & $48(41)$ & $122(29)$ & $257(226,291)$ \\
$t_{\max }, \mathrm{h}$ & $1.5(1.0-4.0)$ & $2.0(1.0-3.0)$ & - \\
$t_{1 / 2}, \mathrm{~h}$ & $2.2(18.2)$ & $4.3(45)$ & - \\
$\mathrm{CL} / F, \mathrm{~L} / \mathrm{h}$ & $109(29)$ & $29(31)$ & - \\
$V_{\mathrm{z} /} F, \mathrm{~L}$ & $341(34)$ & $178(29)$ & - \\
\hline
\end{tabular}

$A U C$ area under the plasma concentration-time curve, $C L / F$ apparent total oral clearance, $C_{\max }$ maximum plasma concentration, $Q D$ once daily, $t_{1 / 2}$ apparent terminal elimination half-life, $t_{\max }$ time of the maximum observed plasma concentration, $V_{z} / F$ apparent volume of distribution during the terminal elimination phase ${ }^{a}$ Geometric mean data (\% coefficient of variation) except where otherwise noted

${ }^{\mathrm{b}}$ Median (min-max)

${ }^{c}$ Ratio of zanubrutinib in combination with itraconazole versus zanubrutinib alone dose of $20 \mathrm{mg}$ of zanubrutinib was conservatively chosen for Part B to study the CYP3A inhibition with itraconazole. Although the $20 \mathrm{mg}$ dose was not studied previously, based on the available PK data from this study and other studies [21], zanubrutinib exhibits dose-proportional and linear PK over the dose range of 20-320 mg. Therefore, the results from the $20 \mathrm{mg}$ dose used in this study can be extrapolated to clinically relevant doses such as $160 \mathrm{mg}$ BID.

The half-life after administration of the $320 \mathrm{mg}$ dose without rifampin was $6.8 \mathrm{~h}$, which was longer than the $2-4 \mathrm{~h}$ half-life observed in previous studies in patients with B-cell malignancies. The difference may be attributed to the different PK sampling scheme used in this study where PK was followed until $48 \mathrm{~h}$ post-dose. In patient studies, PK was generally assessed only for $8 \mathrm{~h}$ post-dose [21] to improve patient convenience, and the half-life may have been underestimated in patients.
Asian and non-Asian healthy subjects were enrolled in this dedicated DDI study to assess any ethnic differences in PK and to support dose selection and clinical development of zanubrutinib in Asia. The exposure of zanubrutinib in Asian subjects was comparable with the non-Asian subjects at both 20-mg and 320-mg doses, and the magnitude of interaction with rifampin and itraconazole was also comparable between the Asian and non-Asian subjects. These results confirm that there are no significant ethnic differences in PK of zanubrutinib, and dose-adjustments are not required in Asian patients. The current study provides a reliable assessment of ethnic comparisons of PK as part of a dedicated clinical pharmacology study in healthy subjects when cross-study comparisons can be challenging in patients because of the variability in PK and underlying comorbidities for a sensitive CYP3A substrate. 
(a)

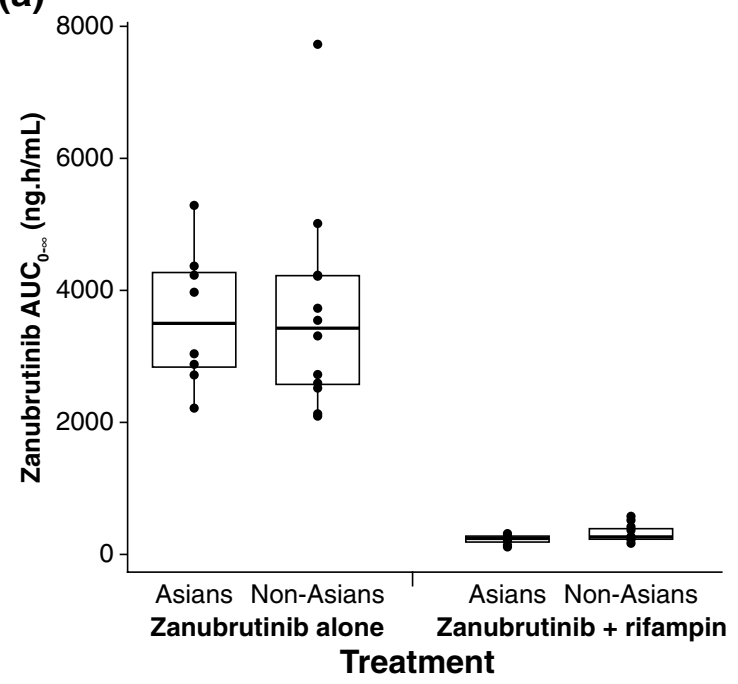

(c)

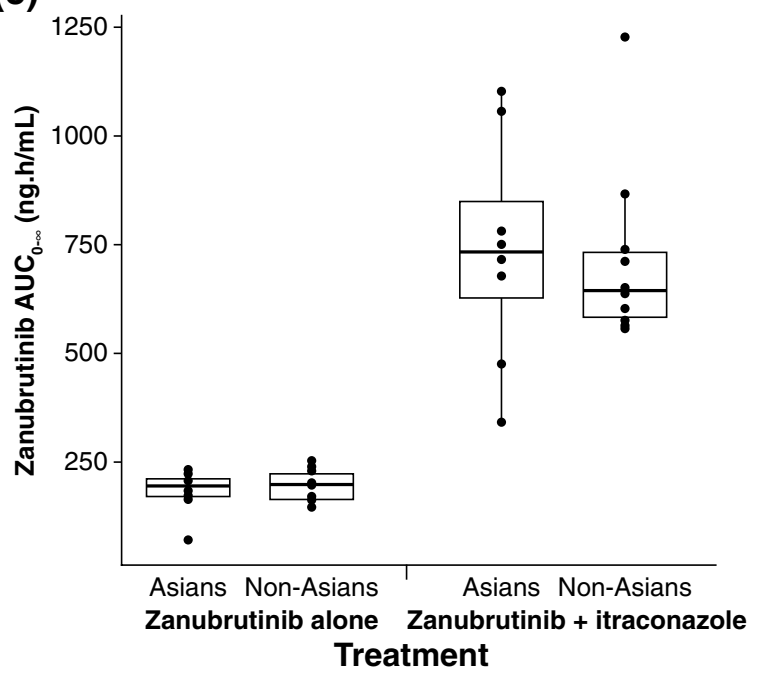

Fig. 2 Comparative box plots of area under the plasma concentration-time curve from $0 \mathrm{~h}$ to infinity $\left(\mathrm{AUC}_{0-\infty}, \mathrm{ng} \cdot \mathrm{h} / \mathrm{mL}\right)$ and maximal plasma concentration $\left(C_{\max } ; \mathrm{ng} / \mathrm{mL}\right)$ in Asian and non-Asian) subjects in $\mathbf{a}, \mathbf{b}$ the absence and presence of rifampin and $\mathbf{c}, \mathbf{d}$ in the absence

Fungal and bacterial infections are commonly observed in patients with B-cell malignancies and may require treatment with medications that are strong or moderate inhibitors of CYP3A such as voriconazole and posaconazole. In these instances of co-medication with CYP3A inhibitors, it would be ideal for patients to continue BTK inhibitor therapy, because it has been demonstrated that dose interruptions with BTK inhibitors can affect their efficacy. For example, patients with chronic lymphocytic leukemia/small lymphocytic lymphoma missing $\geq 8$ consecutive days of ibrutinib had a shorter progression-free survival compared with those missing $<8$ days [29]. Based on the magnitude of
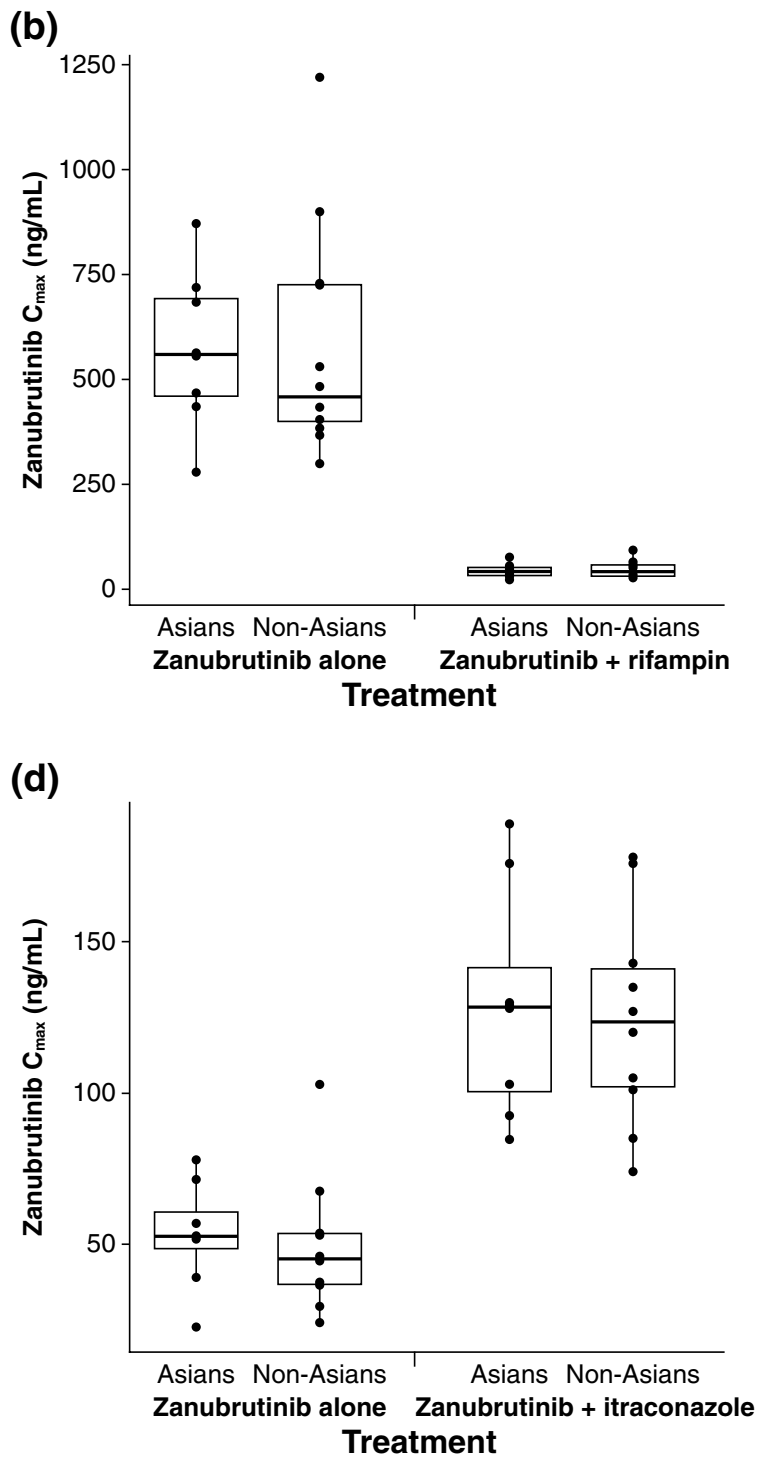

and presence of itraconazole. The box plot represents 25th and 75th percentiles; whiskers extend to 5th and 95th percentiles. Median is indicated by a line within the box, and circles represent values for individual subject

interaction with the strong CYP3A inhibitor itraconazole in this study ( $<4$-fold increase in AUC), it is anticipated that patients taking zanubrutinib may not require dose interruptions and could continue treatment with a lower dose when coadministered with a strong inhibitor of CYP3A to avoid exceeding exposures associated with the maximum clinically tested dose of $320 \mathrm{mg}$ daily.

The results from this DDI study will be used to refine existing in silico physiologically-based PK (PBPK) simulations (unpublished) and assess the impact of moderate and weak CYP3A inhibitors and inducers on the PK of zanubrutinib. Findings from this clinical study and the PBPK 
simulations in conjunction with safety and efficacy data from clinical studies will be used to recommend appropriate dose modifications when patients are required to take zanubrutinib concomitantly with moderate or strong inhibitors and inducers of CYP3A.

Single doses of $320 \mathrm{mg}$ and $20 \mathrm{mg}$ zanubrutinib administered alone or co-administered with $600 \mathrm{mg}$ rifampin and $200 \mathrm{mg}$ itraconazole, respectively, were well tolerated in healthy subjects in this study.

\section{Conclusions}

The results from this DDI study confirm that zanubrutinib is primarily metabolized by CYP3A in humans. PK of zanubrutinib was comparable between Asian and non-Asian subjects and, therefore, no dose modifications are necessary for zanubrutinib in these ethnic populations.

Acknowledgements We thank all the participants in the study. Editorial support for this manuscript was provided by BioConnections. We thank Ashutosh Jindal for graphics support. The study was sponsored by BeiGene, USA.

Funding This study was sponsored by BeiGene, USA.

\section{Compliance with ethical standards}

Conflict of interest Song Mu, Zhiyu Tang, William Novotny, Manal Tawashi, Ta-Kai Li, Ying Ou, and Srikumar Sahasranaman are employees of BeiGene. The study was sponsored and funded by BeiGene, USA.

Open Access This article is licensed under a Creative Commons Attribution 4.0 International License, which permits use, sharing, adaptation, distribution and reproduction in any medium or format, as long as you give appropriate credit to the original author(s) and the source, provide a link to the Creative Commons licence, and indicate if changes were made. The images or other third party material in this article are included in the article's Creative Commons licence, unless indicated otherwise in a credit line to the material. If material is not included in the article's Creative Commons licence and your intended use is not permitted by statutory regulation or exceeds the permitted use, you will need to obtain permission directly from the copyright holder. To view a copy of this licence, visit http://creativecommons.org/licenses/by/4.0/.

\section{References}

1. Ponader S, Burger JA (2014) Bruton's tyrosine kinase: from $\mathrm{X}$-linked agammaglobulinemia toward targeted therapy for B-cell malignancies. J Clin Oncol 32(17):1830-1839. https://doi. org/10.1200/JCO.2013.53.1046

2. Niemann CU, Wiestner A (2013) B-cell receptor signaling as a driver of lymphoma development and evolution. Semin Cancer Biol 23(6):410-421. https://doi.org/10.1016/j.semca ncer.2013.09.001

3. de Rooij MF, Kuil A, Geest CR, Eldering E, Chang BY, Buggy JJ, Pals ST, Spaargaren M (2012) The clinically active BTK inhibitor
PCI-32765 targets B-cell receptor- and chemokine-controlled adhesion and migration in chronic lymphocytic leukemia. Blood 119(11):(11):2590-2594. https://doi.org/10.1182/blood-2011-11390989

4. Bernard S, Danglade D, Gardano L, Laguillier C, Lazarian G, Roger C, Thieblemont C, Marzec J, Gribben J, Cymbalista F, Varin-Blank N, Ledoux D, Baran-Marszak F (2015) Inhibitors of BCR signalling interrupt the survival signal mediated by the micro-environment in mantle cell lymphoma. Int J Cancer 136(12):2761-2774. https://doi.org/10.1002/ijc.29326

5. Burger JA, Tedeschi A, Barr PM, Robak T, Owen C, Ghia P, Bairey O, Hillmen P, Bartlett NL, Li J, Simpson D, Grosicki S, Devereux S, McCarthy H, Coutre S, Quach H, Gaidano G, Maslyak Z, Stevens DA, Janssens A, Offner F, Mayer J, O’Dwyer M, Hellmann A, Schuh A, Siddiqi T, Polliack A, Tam CS, Suri D, Cheng M, Clow F, Styles L, James DF, Kipps TJ, Investigators R (2015) Ibrutinib as initial therapy for patients with chronic lymphocytic leukemia. N Engl J Med 373(25):2425-2437. https ://doi.org/10.1056/NEJMoa1509388

6. Byrd JC, Furman RR, Coutre SE, Flinn IW, Burger JA, Blum KA, Grant B, Sharman JP, Coleman M, Wierda WG, Jones JA, Zhao W, Heerema NA, Johnson AJ, Sukbuntherng J, Chang BY, Clow F, Hedrick E, Buggy JJ, James DF, O'Brien S (2013) Targeting BTK with ibrutinib in relapsed chronic lymphocytic leukemia. $\mathrm{N}$ Engl J Med 369(1):32-42. https://doi.org/10.1056/NEJMoa1215 637

7. Byrd JC, Brown JR, O'Brien S, Barrientos JC, Kay NE, Reddy NM, Coutre S, Tam CS, Mulligan SP, Jaeger U, Devereux S, Barr PM, Furman RR, Kipps TJ, Cymbalista F, Pocock C, Thornton P, Caligaris-Cappio F, Robak T, Delgado J, Schuster SJ, Montillo M, Schuh A, de Vos S, Gill D, Bloor A, Dearden C, Moreno C, Jones JJ, Chu AD, Fardis M, McGreivy J, Clow F, James DF, Hillmen P, Investigators R (2014) Ibrutinib versus ofatumumab in previously treated chronic lymphoid leukemia. N Engl J Med 371(3):213-223. https://doi.org/10.1056/NEJMoa1400376

8. Farooqui MZ, Valdez J, Martyr S, Aue G, Saba N, Niemann CU, Herman SE, Tian X, Marti G, Soto S, Hughes TE, Jones J, Lipsky A, Pittaluga S, Stetler-Stevenson M, Yuan C, Lee YS, Pedersen LB, Geisler CH, Calvo KR, Arthur DC, Maric I, Childs R, Young NS, Wiestner A (2015) Ibrutinib for previously untreated and relapsed or refractory chronic lymphocytic leukaemia with TP53 aberrations: a phase 2, single-arm trial. Lancet Oncol 16(2):169176. https://doi.org/10.1016/S1470-2045(14)71182-9

9. Maddocks K, Jones JA (2016) Bruton tyrosine kinase inhibition in chronic lymphocytic leukemia. Semin Oncol 43(2):251-259. https://doi.org/10.1053/j.seminoncol.2016.02.008

10. Wang ML, Blum KA, Martin P, Goy A, Auer R, Kahl BS, Jurczak W, Advani RH, Romaguera JE, Williams ME, Barrientos JC, Chmielowska E, Radford J, Stilgenbauer S, Dreyling M, Jedrzejczak WW, Johnson P, Spurgeon SE, Zhang L, Baher L, Cheng M, Lee D, Beaupre DM, Rule S (2015) Long-term follow-up of MCL patients treated with single-agent ibrutinib: updated safety and efficacy results. Blood 126(6):739-745. https://doi.org/10.1182/ blood-2015-03-635326

11. Wang ML, Rule S, Martin P, Goy A, Auer R, Kahl BS, Jurczak W, Advani RH, Romaguera JE, Williams ME, Barrientos JC, Chmielowska E, Radford J, Stilgenbauer S, Dreyling M, Jedrzejczak WW, Johnson P, Spurgeon SE, Li L, Zhang L, Newberry K, Ou Z, Cheng N, Fang B, McGreivy J, Clow F, Buggy JJ, Chang BY, Beaupre DM, Kunkel LA, Blum KA (2013) Targeting BTK with ibrutinib in relapsed or refractory mantle-cell lymphoma. N Engl J Med 369(6):507-516. https://doi.org/10.1056/NEJMo a1306220

12. Treon SP, Tripsas CK, Meid K, Warren D, Varma G, Green R, Argyropoulos KV, Yang G, Cao Y, Xu L, Patterson CJ, Rodig S, Zehnder JL, Aster JC, Harris NL, Kanan S, Ghobrial I, Castillo JJ, 
Laubach JP, Hunter ZR, Salman Z, Li J, Cheng M, Clow F, Graef T, Palomba ML, Advani RH (2015) Ibrutinib in previously treated Waldenstrom's macroglobulinemia. N Engl J Med 372(15):1430 1440. https://doi.org/10.1056/NEJMoa1501548

13. Dimopoulos MA, Trotman J, Tedeschi A, Matous JV, Macdonald D, Tam C, Tournilhac O, Ma S, Oriol A, Heffner LT, Shustik C, Garcia-Sanz R, Cornell RF, de Larrea CF, Castillo JJ, Granell M, Kyrtsonis MC, Leblond V, Symeonidis A, Kastritis E, Singh P, Li J, Graef T, Bilotti E, Treon S, Buske C, i NSG, the European Consortium for Waldenstrom's M (2017) Ibrutinib for patients with rituximab-refractory Waldenstrom's macroglobulinaemia (iNNOVATE): an open-label substudy of an international, multicentre, phase 3 trial. Lancet Oncol 18(2):241-250. https://doi. org/10.1016/S1470-2045(16)30632-5

14. Li N, Sun Z, Liu Y, Guo M, Zhang Y, Zhou D, Zhang B, Su D, Zhang S, Han J, Gao Y, Guo Y, Wang Z, Wei M, Luo L, Wang L (2015) Abstract 2597: BGB-3111 is a novel and highly selective Bruton's tyrosine kinase (BTK) inhibitor. Can Res 75(15 Supplement):2597-2597. https://doi.org/10.1158/1538-7445.Am201 $5-2597$

15. Song Y, Zhou K, Zou D, Zhou J, Hu J, Yang H, Zhang H, Ji J, Xu W, Jin J, Lv F, Feng R, Gao S, Zhou D, Guo H, Wang A, Hilger J, Huang J, Novotny W, Osman M, Zhu J (2018) Safety and activity of the investigational bruton tyrosine kinase inhibitor zanubrutinib (BGB-3111) in patients with mantle cell lymphoma from a phase 2 trial. Blood 132(Suppl 1):148-148. https://doi.org/10.1182/ blood-2018-99-117956

16. Tam C, Grigg AP, Opat S, Ku M, Gilbertson M, Anderson MA, Seymour JF, Ritchie DS, Dicorleto C, Dimovski B, Hedrick E, Yang J, Wang L, Luo L, Xue L, Roberts AW (2015) The BTK inhibitor, BGB-3111, is safe, tolerable, and highly active in patients with relapsed/ refractory B-cell malignancies: initial report of a phase 1 first-in-human trial. Blood 126(23):832-832

17. Tam CS, Wang M, Simpson D, Opat S, Cull G, Munoz J, Phillips TJ, Kim W-S, Hilger J, Huang J, Novotny W, Trotman J (2018) Updated safety and activity of the investigational bruton tyrosine kinase inhibitor zanubrutinib (BGB-3111) in patients with mantle cell lymphoma. Blood 132(Suppl 1):1592-1592. https://doi. org/10.1182/blood-2018-99-117224

18. Tam CS, LeBlond V, Novotny W, Owen RG, Tedeschi A, Atwal S, Cohen A, Huang J, Buske C (2018) A head-to-head Phase III study comparing zanubrutinib versus ibrutinib in patients with Waldenstrom macroglobulinemia. Future Oncol 14(22):22292237. https://doi.org/10.2217/fon-2018-0163

19. A Study of Zanubrutinib (BGB-3111) Versus ibrutinib in patients with relapsed/refractory chronic lymphocytic leukemia. Available from: https://clinicaltrials.gov/ct2/show/NCT03734016. NLM identifier: NCT03734016. Accessed 8 May 2019

20. Hillmen P, Brown JR, Kahl BS, Ghia P, Robak T, Marimpietri C, Cohen A, Huang J, Tam CSL (2018) Phase 3 zanubrutinib (BGB-3111) vs bendamustine + rituximab (BR) in patients (pts) with treatment-naïve (TN) chronic lymphocytic leukemia/small lymphocytic lymphoma (CLL/SLL). J Clin Oncol 36 (15suppl): 581-7581. DOI: 10.1200/JCO.2018.36.15_suppl.TPS7581.

21. Tam CS, Trotman J, Opat S, Burger JA, Cull G, Gottlieb D, Harrup R, Johnston PB, Marlton P, Munoz J, Seymour JF, Simpson D, Tedeschi A, Elstrom R, Yu Y, Tang Z, Han L, Huang J, Novotny W, Wang L, Roberts AW (2019) Phase 1 study of the selective BTK inhibitor zanubrutinib in B-cell malignancies and safety and efficacy evaluation in CLL. Blood 134(11):851-859. https://doi. org/10.1182/blood.2019001160

22. Nosari A (2012) Infectious complications in chronic lymphocytic leukemia. Mediterr J Hematol Infect Dis 4(1):e2012070. https:// doi.org/10.4084/MJHID.2012.070

23. Nucci M (2012) Use of antifungal drugs in hematology. Rev Bras Hematol Hemoter 34(5):383-391. https://doi.org/10.5581/15168484.20120095

24. Bruggemann RJ, Alffenaar JW, Blijlevens NM, Billaud EM, Kosterink JG, Verweij PE, Burger DM (2009) Clinical relevance of the pharmacokinetic interactions of azole antifungal drugs with other coadministered agents. Clin Infect Dis 48(10):1441-1458. https://doi.org/10.1086/598327

25. de Jong J, Skee D, Murphy J, Sukbuntherng J, Hellemans P, Smit J, de Vries R, Jiao JJ, Snoeys J, Mannaert E (2015) Effect of CYP3A perpetrators on ibrutinib exposure in healthy participants. Pharmacol Res Perspect 3(4):e00156. https://doi.org/10.1002/ prp2.156

26. Srinivas NR (2016) Pharmacokinetic interaction of rifampicin with oral versus intravenous anticancer drugs: challenges, dilemmas and paradoxical effects due to multiple mechanisms. Drugs R D 16(2):141-148. https://doi.org/10.1007/s40268-016-0133-0

27. Liu L, Bello A, Dresser MJ, Heald D, Komjathy SF, O’Mara E, Rogge M, Stoch SA, Robertson SM (2016) Best practices for the use of itraconazole as a replacement for ketoconazole in drug-drug interaction studies. J Clin Pharmacol 56(2):143-151. https://doi. org/10.1002/jcph.562

28. Calquence(r) (acalabrutinib) [package insert] (2017) Acerta Pharma, South San Francisco

29. Barr PM, Brown JR, Hillmen P, O'Brien S, Barrientos JC, Reddy NM, Coutre S, Mulligan SP, Jaeger U, Furman RR, Cymbalista F, Montillo M, Dearden C, Robak T, Moreno C, Pagel JM, Burger JA, Suzuki S, Sukbuntherng J, Cole G, James DF, Byrd JC (2017) Impact of ibrutinib dose adherence on therapeutic efficacy in patients with previously treated CLL/SLL. Blood 129(19):26122615. https://doi.org/10.1182/blood-2016-12-737346

Publisher's Note Springer Nature remains neutral with regard to jurisdictional claims in published maps and institutional affiliations. 